Article

\title{
Impact of Alkali and Silane Treatment on Hemp/PLA Composites' Performance: From Micro to Macro Scale
}

\author{
Percy Festus Alao ${ }^{1, *(\mathbb{D})}$, Laetitia Marrot ${ }^{2,3}{ }^{\mathbb{D}}$, Michael David Burnard ${ }^{2,3}$, Gregor Lavrič ${ }^{4}$, Mart Saarna ${ }^{5} \mathbb{D}$ \\ and Jaan Kers ${ }^{1}$
}

1 Department of Material and Environmental Technology, Tallinn University of Technology, Ehitajate tee 5, 19086 Tallinn, Estonia; jaan.kers@taltech.ee

2 InnoRenew CoE, Livade 6, 6310 Izola, Slovenia; laetitia.marrot@innorenew.eu (L.M.); mike.burnard@innorenew.eu (M.D.B.)

3 Andrej Marušič Institute, University of Primorska, Muzejski trg 2, 6000 Koper, Slovenia

4 Pulp and Paper Institute, Bogišićeva 8, 1000 Ljubljana, Slovenia; gregor.lavric@icp-lj.si

5 Department of Mechanical and Industrial Engineering, Tallinn University of Technology, Ehitajate tee 5, 19086 Tallinn, Estonia; mart.saarna@taltech.ee

* Correspondence: percy.alao@taltech.ee

Citation: Alao, P.F.; Marrot, L.; Burnard, M.D.; Lavrič, G.; Saarna, M.; Kers, J. Impact of Alkali and Silane Treatment on Hemp/PLA Composites' Performance: From Micro to Macro Scale. Polymers 2021, 13, 851. https://doi.org/10.3390/ polym 13060851

Academic Editor: Ralf Schledjewski

Received: 18 February 2021

Accepted: 5 March 2021

Published: 10 March 2021

Publisher's Note: MDPI stays neutral with regard to jurisdictional claims in published maps and institutional affiliations.

Copyright: (c) 2021 by the authors. Licensee MDPI, Basel, Switzerland. This article is an open access article distributed under the terms and conditions of the Creative Commons Attribution (CC BY) license (https:// creativecommons.org/licenses/by/ $4.0 /)$.

\begin{abstract}
This study investigated the effect of hemp fiber pretreatments (water and sodium hydroxide) combined with silane treatment, first on the fiber properties (microscale) and then on polylactide (PLA) composite properties (macroscale). At the microscale, Fourier transform infrared, thermogravimetric analysis, and scanning electron microscopy investigations highlighted structural alterations in the fibers, with the removal of targeted components and rearrangement in the cell wall. These structural changes influenced unitary fiber properties. At the macroscale, both pretreatments increased the composites' tensile properties, despite their negative impact on fiber performance. Additionally, silane treatment improved composite performance thanks to higher performance of the fibers themselves and improved fiber compatibility with the PLA matrix brought on by the silane couplings. PLA composites reinforced by $30 \mathrm{wt} . \%$ alkali and silane treated hemp fibers exhibited the highest tensile strength (62 MPa), flexural strength (113 MPa), and Young's modulus (7.6 GPa). Overall, the paper demonstrates the applicability of locally grown, frost-retted hemp fibers for the development of bio-based composites with low density (1.13 to $1.23 \mathrm{~g} \mathrm{~cm}^{-3}$ ).
\end{abstract}

Keywords: hemp fibers; polylactic acid; biocomposite materials; mechanical properties; surface treatments

\section{Introduction}

The development of structural plant fiber composite components started about 80 years ago [1] and there is considerable interest in them nowadays because of the growing environmental and ecological pressures facing industries. Characteristics and properties of biocomposites have evolved, but improvements are still needed for the effective and durable use of plant fiber reinforcement of composites. While flax has been extensively studied in this aim [1], hemp fibers also show interesting specific properties for the reinforcement of composites [2]. The rougher surface of hemp fibers compared with flax fibers could positively influence the fiber/matrix adhesion [3]. Moreover, an increase in fiber surface roughness was found to facilitate the capillary flow in fibrous porous media, which suggests a smooth composite production process [4]. Adhesion between natural fibers and thermoplastic matrices is always questioned due to the hydrophilic character of natural fibers, which induces a decrease in the interfacial contact between the natural fiber and the matrix polymer, leads to dimensional changes and lower mechanical performance from possible moisture uptake in the composite and provides favorable conditions for the development of microorganisms. In the literature, various treatments have been 
investigated to improve adhesion between natural fibers and matrices, either by cleaning impurities from the surface of the fibers or by creating chemical bonding between the two components with coupling agent agents [5]. Bourmaud et al. [6] used a soft water treatment to clean flax fibers. Alkali treatments are used to remove hemicelluloses from natural fibers and can also partially remove other non-cellulosic components like lignin and pectin [7]. The removal of hemicellulose and lignin cover materials exposes more cellulose hydroxyl groups to alkali, which reduces the hydrophilic nature of natural fibers by replacing cellulose hydroxyl groups with less hydrophilic $\mathrm{O}-\mathrm{Na}^{+}$groups (Fiber-H $+\mathrm{NaOH}->$ Fiber- $\mathrm{O}^{-} \mathrm{Na}^{+}+\mathrm{H}_{2} \mathrm{O}$ ) and improves adhesion between fibers and matrix binders [5]. Silane coupling agents are used to improve the wettability of fibers by matrix polymers through graft copolymerization. Stable covalent bonds are eventually formed between alkoxy silanes and hydroxyl groups on the fiber surface $[5,8]$.

Fiber treatments are often conducted to improve matrix adhesion within a composite, but they may degrade the fibers' mechanical performance at the same time [9]. As highlighted by Liu et al. [5], the effect of treatment on the mechanical properties of the fibers and resulting composites should be understood to provide effective and profitable treatments. Moreover, Merotte et al. [3] showed that the improvement of interfacial shear strength brought on by a coupling agent (MAPP vs. PP) had much less influence on the mechanical properties of the composite than the nature of the fibers (flax or hemp) and their individualization. With low interfacial shear strength systems, such as plant fibers associated with polyolefin matrices like polypropylene, polyethylene, or polylactic acid (PLA), macroscale mechanical properties are governed by the fibers' mechanical properties and bonding area rather than by interfacial bond strength [3]. A composite's properties depend on multiple fiber parameters (mechanical performance, content, aspect ratio, orientation, individualization and dispersion [10], adhesion with matrix [11], and porosities), so it is difficult to unquestionably attribute an improvement or diminution of the composite mechanical properties to fiber treatment.

This study investigates step by step the effect of different surface pretreatments (water and sodium hydroxide) combined with a silane treatment of an Estonian cultivated and frost retted hemp fiber, first on the single fiber microscale properties and then on the macroscale mechanical performance of their composites with a PLA matrix. This work aims to:

i. Show an accurate inference of the fiber pretreatments and treatment on the composite's mechanical performance by linking the effects reported at the microscale, specifically the impact of the treatments on the fibers' tensile properties, to their overall impact at the macroscale. The dual scales of observation bring a complementarity to the analysis, which is not often reported in the literature. Fiber composition, tensile mechanical properties, individualization, and dispersion are thoroughly studied, while the fiber content, aspect ratio, and orientation are carefully maintained as equivalent for all the composite formulations.

ii. Provide first-hand information on the suitability of Estonian hemp fibers for composite reinforcement. Indeed, these fibers are a by-product of cannabidiol production for medicinal applications and are currently considered as a waste. PLA is selected for its renewable and compostable properties, along with its comparable performance to common petrochemically derived alternatives [12]. Figure 1 presents a schematic of the main idea and procedure of this study. 


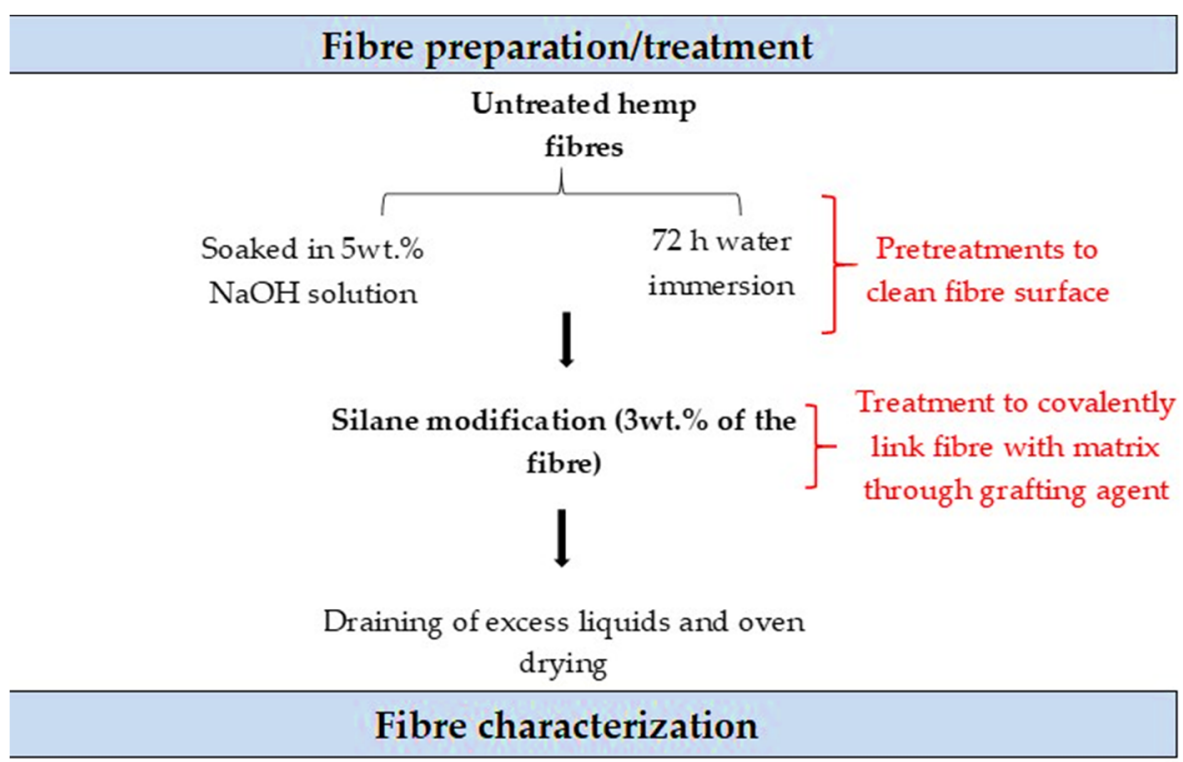

Assessment of the impact of combined treatments at the fibre scale

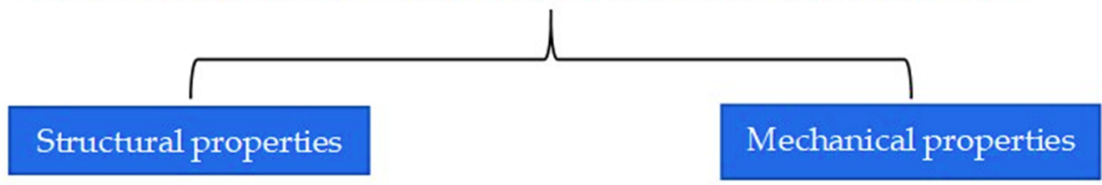

\section{Composite fabrication and testing}

Assessment of the impact of combined treatments at the composite scale

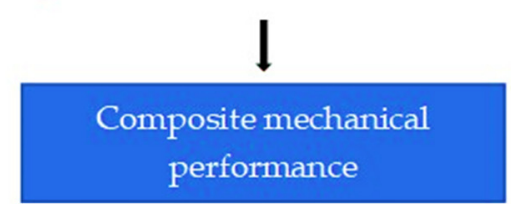

Figure 1. Schematic description of the current research aim and procedure.

\section{Materials and Methods}

2.1. Materials

Hemp fibers (Cannabis sativa, Tisza, Hungary) grown in Saaremaa, Estonia were used. Their properties have been characterized and described in previous work [13]. The stems were industrially decorticated by a mechanical process. PLA fibers (IngeoTM 4043D) from NatureWorks (Minnetonka, MN, USA) were used for the research. The polymer was $60 \mathrm{~mm}$ long, with a round cross-section, a finesse of $6.7 \mathrm{dtex}$ and a density of $1.24 \mathrm{~g} \mathrm{~cm}^{-3}$.

\subsection{Fiber Surface Treatments}

\subsubsection{Water Treatment}

Fibers were dried in an oven at $80{ }^{\circ} \mathrm{C}$ until constant weight to remove excess moisture and then washed by soaking in distilled water for $72 \mathrm{~h}$ at $23^{\circ} \mathrm{C}$ according to Bourmaud et al. [6].

\subsubsection{Alkali Treatment}

Hemp fibers were treated with a solution of $5 \mathrm{wt}$ \% sodium hydroxide $(\mathrm{NaOH})$. (Sigma-Aldrich, Saint Louis, MO, USA) Sodium (Na) granules were used in preparing the $\mathrm{NaOH}$ solution. Hemp fibers were soaked in the solution at room temperature $\left(23^{\circ} \mathrm{C}\right)$ for $4 \mathrm{~h}$. Fibers were then washed in tap water to remove residual alkali by measuring the wastewater's $\mathrm{pH}$ until it was about 7 . Finally, the fibers were oven-dried at $80^{\circ} \mathrm{C}$ until constant weight. 


\subsubsection{Silane Treatment}

Hemp fibers were treated with an ethanol and water solution containing $3 \mathrm{wt} . \%$ silane coupling agent (3-Aminopropyl-triethoxy silane) whose structure is presented in Figure 2. The amount of silane was relative to the weight of hemp fibers. Silane was previously pre-hydrolyzed at room temperature for $2 \mathrm{~h}$ in an $80 / 20 \mathrm{vol} \%$ solution of ethanol/water. The $\mathrm{pH}$ of the solution was adjusted to 5 using acetic acid. Hemp fibers were soaked in the solution at room temperature for $2 \mathrm{~h}$. Then, the hemp fibers were filtered and oven-dried at $80^{\circ} \mathrm{C}$ until constant weight.

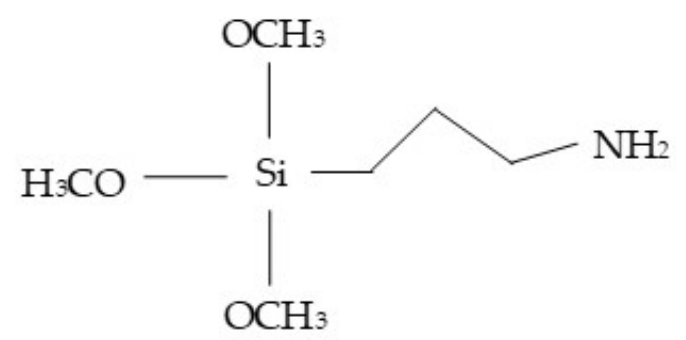

Figure 2. Structure of 3-Aminopropyl-triethoxy silane.

\subsection{Fabrication of the Hemp Reinforced PLA (HPLA) Composites}

Untreated $\left(\mathrm{U}_{\mathrm{f}}\right)$ and treated (distilled water $\left(\mathrm{W}_{\mathrm{f}}\right)$, water + silane $\left(\mathrm{WS}_{\mathrm{f}}\right)$, alkali $\left(\mathrm{A}_{\mathrm{f}}\right)$ and alkali + silane $\left(\mathrm{AS}_{\mathrm{f}}\right)$ ) fibers were combined with PLA by compression moulding. Two composite types were produced from $30 \mathrm{wt} . \%$ (160.5 $\mathrm{g}$ of hemp fibers) + PLA and $50 \mathrm{wt} . \%$ (267.5 g of hemp fibers) + PLA in a metal frame $(450 \mathrm{~mm} \times 450 \mathrm{~mm} \times 2 \mathrm{~mm})$ using a hot press. Hemp and PLA fibers were mixed using a wide classic drum carder (300 mm batt width, 72 teeth per inch (tpi) and $100 \mathrm{~g}$ capacity). The mixture was dried in an oven for $4 \mathrm{~h}$ at $80^{\circ} \mathrm{C}$ before compression at $180^{\circ} \mathrm{C}$ and $3 \mathrm{MPa}$ for $10 \mathrm{~min}$. Neat PLA boards were also fabricated as a control. Abbreviations and descriptions for the composite boards are presented in Table 1.

Table 1. Nomenclature used for polylactic acid (PLA), untreated and treated hemp fiber reinforced polylactide composites.

\begin{tabular}{cc}
\hline Abbreviation & Samples \\
\hline Neat PLA & Unreinforced polylactic acid boards from 100\% PLA fibers. \\
UH & Untreated hemp fiber $\left(\mathrm{U}_{\mathrm{f}}\right)$ reinforced polylactide composites. \\
WH & Water-treated hemp fiber $\left(\mathrm{W}_{\mathrm{f}}\right)$ reinforced polylactide composites. \\
WSH & Combined water- and silane- $\left(\mathrm{WS}_{\mathrm{f}}\right)$ treated hemp fiber reinforced polylactide composites. \\
AH & Alkali-treated hemp fiber $\left(\mathrm{A}_{\mathrm{f}}\right)$ reinforced polylactide composites. \\
ASH & Combined alkali- and silane- $\left(\mathrm{AS}_{\mathrm{f}}\right)$ treated hemp fiber reinforced polylactide composites. \\
\hline
\end{tabular}

\subsection{Characterization of Hemp Fibers and HPLA Composites}

2.4.1. Chemical Composition by Fourier Transform Infrared (FTIR)

The spectroscopy was carried out to qualitatively identify the constituents of untreated and chemically treated hemp fibers and assess the effects of the treatments on the composition. Measurements were performed on a Nicolet ${ }^{\mathrm{TM}}$ iS50 FTIR Spectrometer (Thermo Fisher Scientific, Waltham, MA, USA) with ATR module from Thermo Scientific ${ }^{\mathrm{TM}}$. The fiber batches were conditioned in the spectrometer room for two weeks before analysis to ensure stable moisture content (MC). Analysis was performed on the fibers (not grounded) to preserve the internal organization of components. Bundles of hemp fibers were twisted by hand and placed on the ATR crystal. All FTIR spectra were collected with a spectrum resolution of $4 \mathrm{~cm}^{-1}$. A background scan of clean $\mathrm{Zn}-\mathrm{Se}$ diamond crystal was processed before the sample scanning procedures. Ten replicates were tested for each batch with 22 scans per sample. 


\subsubsection{Chemical Composition by Thermogravimetric Analysis (TGA)}

Thermogravimetric analysis was performed on untreated and treated hemp fibers. The experiments were carried out using a NETZSCH STA 449F3 (NETZSCH-Gerätebau $\mathrm{GmbH}$, Wittelsbacherstraße, Germany) in a nitrogen atmosphere (20 $\mathrm{mL}$ per min). For each sample (approximately $6 \mathrm{mg}$ ), three measurements were performed, beginning with an isothermal segment at $40{ }^{\circ} \mathrm{C}$ for $1 \mathrm{~min}$, followed by dynamic heating from $40{ }^{\circ} \mathrm{C}$ to $600{ }^{\circ} \mathrm{C}$ at the rate of $2{ }^{\circ} \mathrm{C} \mathrm{min}-1$. Samples were held in an aluminum pan $\left(\mathrm{Al}_{2} \mathrm{O}_{3}\right)$. Specimens were kept in the testing room at a relative humidity of $43 \pm 10 \%$ and a temperature of $22 \pm 1{ }^{\circ} \mathrm{C}$ for one week before the test.

\subsubsection{Microscopical Observations by Scanning Electron Microscopy (SEM)}

SEM images of the fibers and composites were observed using a Zeiss Ultra 55 (FELMIZFE, Steyrergasse, Austria) at $20 \mathrm{kV}$, depth of $100 \mathrm{~nm}$ and resolution of 50,000. For this observation, samples were carbon glued on an aluminum stub and then coated with an alloy of $2 \mathrm{~nm}$ thick gold $(\mathrm{Au}) /$ palladium $(\mathrm{Pd})$ layer $(80 / 20)$. For the composite samples, each specimen was mounted into Buehler EpoThin Epoxy glue before coating and observation.

\subsection{Mechanical Properties of Unitary Hemp Fibers and Hemp/PLA Composites}

Tensile tests were carried out on single hemp fibers for the five batches on a Zwick Roell Z010 (ZwickRoell GmbH \& Co. KG, August-Nagel-Straße, Germany) tensile machine equipped with a $20 \mathrm{~N}$ measuring cell (Class 0.5, ISO 7500-1) at a speed of $1 \mathrm{~mm}$ per min. The gauge length was taken at $10 \mathrm{~mm}$. For each batch, at least 50 fibers were tested. The mean diameter of each fiber was measured before testing (average of 3 points).

Tensile and flexural tests were performed on the composite samples in accordance with EVS-EN ISO 527 (Type 2) and EVS-EN ISO 14,125 (Class II) standard tests, respectively, using an Instron 8516 (Norwood, MS, USA) machine equipped with a load cell of $10 \mathrm{kN}$. The test was done at $(43 \pm 10) \% \mathrm{RH},(22 \pm 1){ }^{\circ} \mathrm{C}$ and test speed of $2 \mathrm{~mm}$ per min. Five (5) replicates per batch were used to evaluate the result, though four replicas were used for tensile strength of the UH composites due to sampling issues during testing. Specimen dimensions for the flexural test were $80 \times 15 \mathrm{~mm}$ and thickness varied from $2-4 \mathrm{~mm}$, while tensile test specimens had a dimension of $250 \mathrm{~mm} \times 25 \mathrm{~mm}$. An Extensometer $\mathrm{L}_{\mathrm{o}}=50 \mathrm{~mm}$ (model 2630-112, $\mathrm{s} / \mathrm{n}$ 937) was attached to the test specimens to determine the elongation before failure. In addition, composite density was determined in accordance with EVS-EN ISO 1183-1 from five replicas, using a Mettler Toledo AX balance. Test pieces were $15 \mathrm{~mm} \times 20 \mathrm{~mm}$ and conditioned following ISO 291 .

\subsection{Statistical Analysis}

Statistical analysis and figures were done in R v4.0.2 (Vienna, Austria) [14] and RStudio v1.3.1073 (Boston, MA, USA) [15] using the tidyverse package [16] for data manipulation and plotting and the emmeans package [17] to compute and extract pairwise comparisons between treatments. The boot package was used to extract bootstrapped estimates and their bias-corrected accelerated (BCA) confidence intervals.

\subsubsection{Statistical Analysis of Fiber Properties}

Separate linear models were fit to each natural log-transformed response (Modulus, Strain and Strength) since the raw response data violated the equal variance assumption for a linear model. Models were fit with pretreatment-treatment interactions and pretreatment conditions only. Interaction models were fit without the raw pretreatment condition (degrees of freedom $=206$ ) and resulted in conditional pairwise comparisons between treatment effects (silane or none) in each pretreatment condition (alkali, water). Pretreatment-only models excluded samples with treatments (degrees of freedom $=143$ ) and resulted in pairwise comparisons between each of the pretreatment conditions (raw, water or alkali). Extracted pairwise comparisons between each treatment were backtransformed to the original response scale and reported as the ratio between medians of the 
compared treatments. $p$-values for pretreatment comparisons were adjusted using Tukey's method for a family of 3 estimates. Significance level for all $p$-values was set to 0.05 .

\subsubsection{Statistical Analysis of Composite Tensile and Flexural Properties}

Linear models were fit for each measured property (flexure strength, flexure modulus, tensile strength and tensile modulus). Both flexure (strength and modulus) and tensile modulus model had 7 and 42 degrees of freedom, while the tensile modulus had 7 and 41 degrees of freedom (due to some testing errors with a specimen). In each case, the response was log-transformed because the linear model's equal variance assumption was violated. Each model was fit to pretreatment and treatment main effects as well as interaction effects between the pretreatment/fiber loading and treatment/fiber loading. Due to sample sizes, linear models and resulting pairwise comparisons were bootstrapped and their BCA confidence intervals calculated. The resulting estimates were the ratios between medians of compared treatments at specified fiber loading levels $(30 \%$ or $50 \%$ ) on the original scale. Reported $p$-values were based on the model values (not the bootstrapped values) and adjusted for a family of 6 comparisons using Tukey's method. The significance level for all $p$-values was set to 0.05 .

\section{Results and Discussion}

\subsection{Chemical Composition by FTIR Analysis}

For easier visualization, the average vertically shifted FTIR spectra are separated into two. Figure $3 a$ displays the FTIR spectra for $U_{f}, W_{f}$, and $A_{f}$, while Figure $3 b$ shows the spectra for $\mathrm{U}_{\mathrm{f}}, \mathrm{WS}_{\mathrm{f}}$, and $\mathrm{AS}_{\mathrm{f}}$. Qualitatively, $\mathrm{U}_{\mathrm{f}}$ and $\mathrm{W}_{\mathrm{f}}$ spectra appear similar; however, there is a higher absorbance in $3000-3600 \mathrm{~cm}^{-1}$ for $\mathrm{W}_{\mathrm{f}}$ compared to $\mathrm{U}_{\mathrm{f}}$. The $3000-3600 \mathrm{~cm}^{-1}$ corresponds to $\mathrm{OH}$ stretching vibrations, an increase of which depicts more $\mathrm{OH}$ functionality and lower hydrophilic properties [18]. This implies that some non-cellulosic polysaccharide was removed from the fiber surface, as shown by Bourmaud et al. [6]. Conversely, the $A_{f}$ spectrum presents peak absence/reduction at about $1735 \mathrm{~cm}^{-1}$ and $1235 \mathrm{~cm}^{-1}$. The peak around $1735 \mathrm{~cm}^{-1}$ corresponds to $\mathrm{C}=\mathrm{O}$ stretching vibration of conjugated carboxylic ester groups [19] of hemicellulose or wax [18], and the peak around $1235 \mathrm{~cm}^{-1}$ corresponds to C-O stretching of lignin acetyl groups $[18,20]$. Furthermore, the peak at $1635 \mathrm{~cm}^{-1}$ that shows $\mathrm{C}=\mathrm{O}$ stretching in conjugated carbonyl of lignin or absorbed water is broader and attenuated [21]. Additionally, oscillations at $2918 \mathrm{~cm}^{-1}$ that correspond to $\mathrm{C}-\mathrm{H}$ stretching in lignin's aromatic hydrocarbon, methoxyl, and methylene groups [9], as well as oscillations at $2850 \mathrm{~cm}^{-1}$ related to symmetric $\mathrm{C}-\mathrm{H}$ stretching of non-aromatic compounds present in the cellulose and hemicellulose components [20], are also reduced. Higher absorbance with better peak definition from $3000-3600 \mathrm{~cm}^{-1}$ is achieved by alkali-treated fibers.

Ostensibly, it appears that the spectrum of $\mathrm{WS}_{\mathrm{f}}$ and $\mathrm{W}_{\mathrm{f}}$ is also similar, but Figure $4 \mathrm{a}$ clearly shows that the additional silane treatment induces a peak shift from $1635 \mathrm{~cm}^{-1}$ to $1624 \mathrm{~cm}^{-1}$ and attenuation at about $1539 \mathrm{~cm}^{-1}, 1369 \mathrm{~cm}^{-1}$, and $1248 \mathrm{~cm}^{-1}$. Similar peak shifts have been reported in past research after silane pretreatments of hemp fibers $[9,18,21]$. This suggests that the ensuing silane treatment led to the extraction of some hemicellulose, wax and lignin fiber contents. In Figure $4 \mathrm{~b}$, it was also discovered that the subsequent silane treatment causes higher peak intensity with new peaks that could be related to $\mathrm{NH}_{2}$ bending vibrations in amino silane between $1500-1680 \mathrm{~cm}^{-1}$, also reported by Panaitescu et al. [21]. We can infer from our results that the water treatment did not affect the lignin content of hemp fibers, but it slightly increased the functional $\mathrm{OH}$ due to the removal of some water-soluble polysaccharides. Alkali treatment was effective in extracting pectins, hemicellulose, and lignin content, and silane treatment showed slight removal of intercellular content, especially for water pretreated hemp fibers with some new peaks that could be due to silane molecule coatings on the fiber surface following water/alkali pretreatments. 

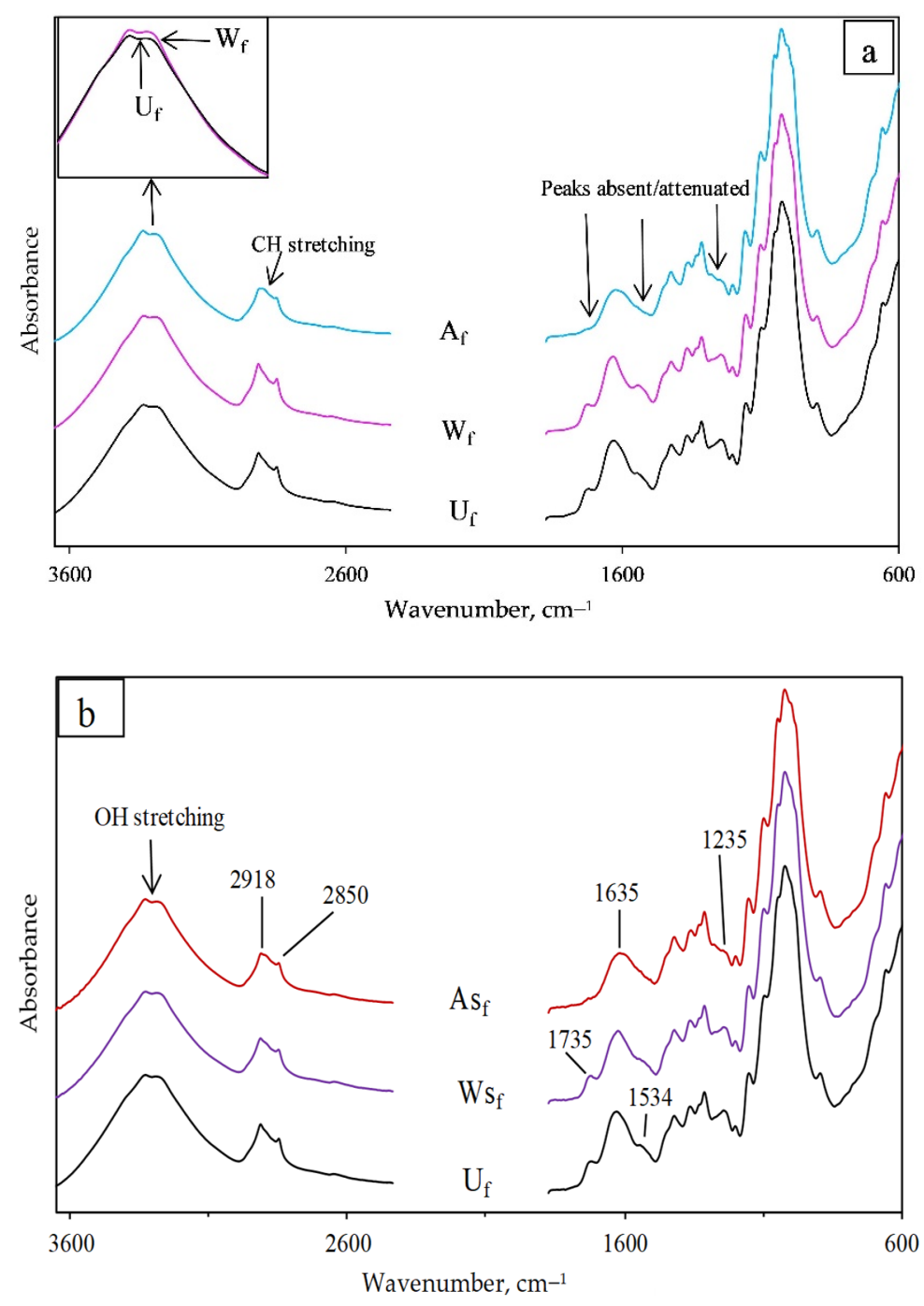

Figure 3. Vertically shifted FTIR spectra for $(a)$ untreated $\left(U_{f}\right)$, distilled water $\left(W_{f}\right)$, and alkali-treated $\left(\mathrm{A}_{\mathrm{f}}\right)$ hemp fibers; $(\mathbf{b}) \mathrm{U}_{\mathrm{f}}$, water + silane $\left(\mathrm{WS}_{\mathrm{f}}\right)$ and alkali + silane $\left(\mathrm{AS}_{\mathrm{f}}\right)$ treated hemp fibers with the wavenumbers for differences observed.
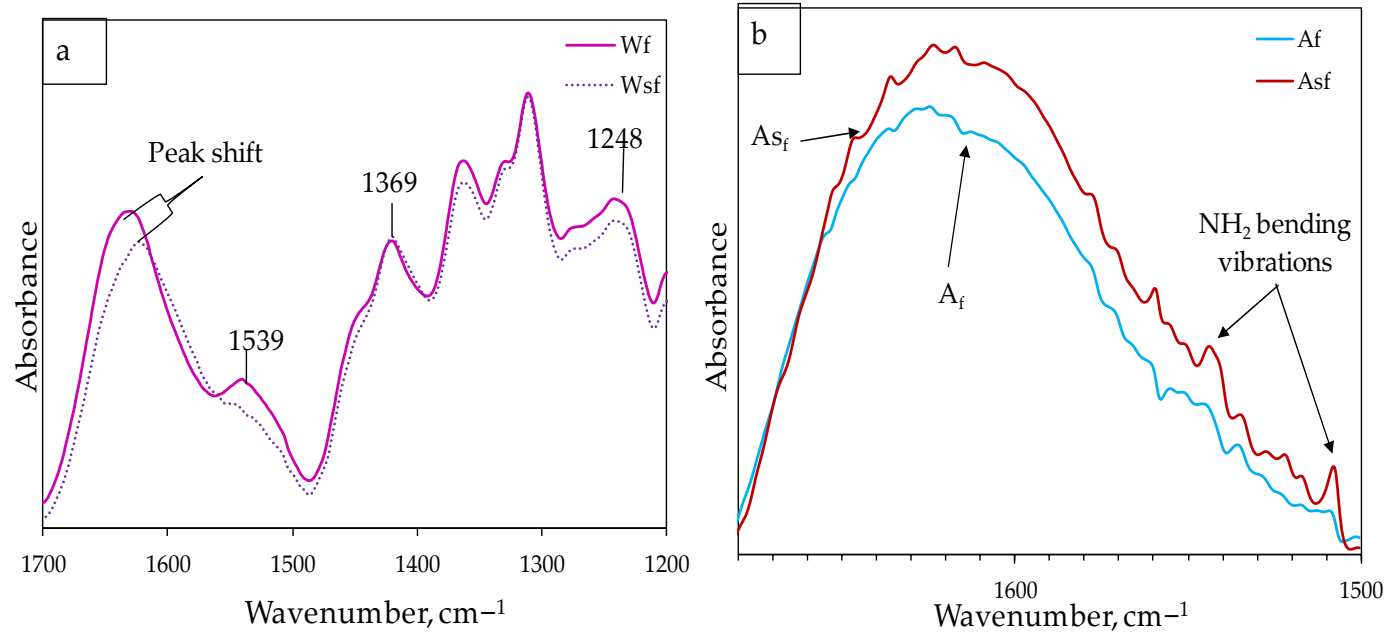

Figure 4. FTIR spectra for (a) degradation of a portion of lignin in $\mathrm{WS}_{\mathrm{f}}$; $(\mathbf{b})$ silane coupling effect after treatment of alkali modified fibers. 


\subsection{Chemical Composition by Thermogravimetric Analysis (TGA)}

TGA curves for all batches (Figure 5a) display two main weight losses, while for clarity, only the differential thermogravimetric analysis (dTGA) (Figure 5b) for untreated, water- and alkali-treated fibers is presented. In Figure 5a, the observed mass loss between $39-160{ }^{\circ} \mathrm{C}$ was attributed to the evaporation of water from the fibers. The estimated mass loss in this temperature range is shown in Table 2. A loss of approximately $1.4 \%$ was obtained for $\mathrm{U}_{\mathrm{f}}$ compared to $0.3 \%$ for the batches of treated fibers. The lower moisture content observed for $\mathrm{W}_{\mathrm{f}}$ and $\mathrm{A}_{\mathrm{f}}$ compared to $\mathrm{U}_{\mathrm{f}}$ is in accordance with the FTIR results for which pretreated fibers showed decreased hydrophilicity associated with the removal of non-cellulosic polysaccharides. Other studies $[18,20]$ reported a similar decrease of mass loss in the $39-160{ }^{\circ} \mathrm{C}$ region for fibers that underwent alkali treatments.
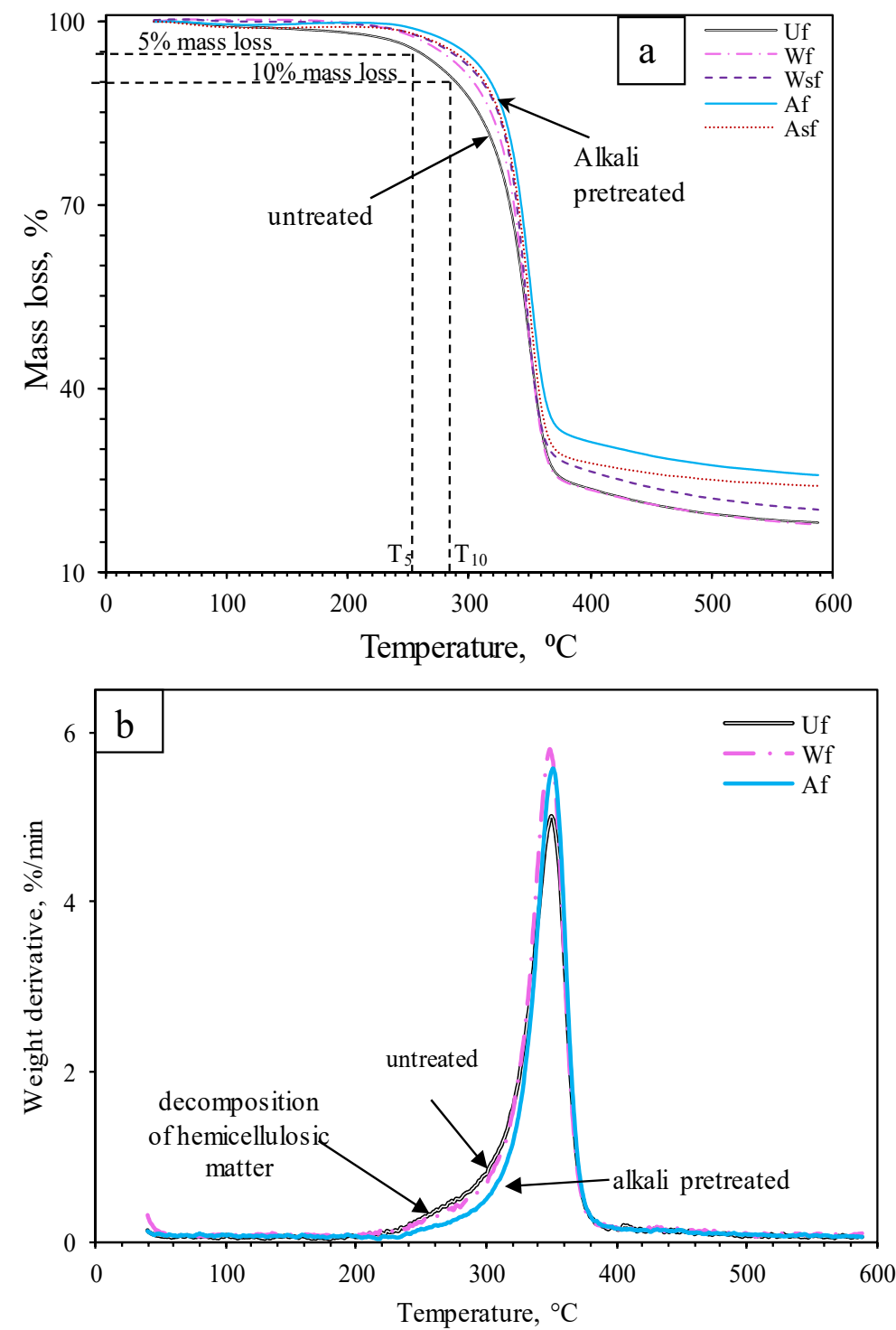

Figure 5. (a) TGA curves for $U_{f}, W_{f}, W_{f}, A_{f}, A_{f} ;(b) d T G A$ curve for $U_{f}, W_{f}$ and $A_{f}$ batches.

The second degradation appears between 160 and $600{ }^{\circ} \mathrm{C}$ with a peak of around $346^{\circ} \mathrm{C}$. Placet et al. [22] highlighted the superimposition of several degradations in this range of temperatures. The majority of hemicellulose matter degrades between 180 and $280^{\circ} \mathrm{C}$, while the remaining hemicelluloses and formed by-products decompose from 280 to $600{ }^{\circ} \mathrm{C}$. However, cellulose decomposes roughly between 325 and $400{ }^{\circ} \mathrm{C}$, and lignin decomposes between 150 and $450{ }^{\circ} \mathrm{C}$. Here, the second degradation corresponds then to 
the decomposition of amorphous polysaccharides (hemicelluloses and pectin) taking place between 180 and $280^{\circ} \mathrm{C}$, where a shoulder is visible on the dTGA curve, in addition to the decomposition of cellulose and lignin constituents and formed by-products. The remaining mass corresponds to the ash or non-polysaccharide contents [6]. The composition of the studied hemp fibers was investigated in previous work [13] and showed cellulose (77.4\%), hemicellulose $(8.3 \%)$, solubles $(12.6 \%)$, and lignin $(1.4 \%)$. To further investigate the fiber treatment's effectiveness, temperatures corresponding to a $5 \%$ weight loss $\left(T_{5}\right)$ and a $10 \%$ weight loss $\left(T_{10}\right)$ were considered (Table 2$)$. It can be seen that after water and alkali pretreatment, the values shifted to higher temperatures (i.e., from $254{ }^{\circ} \mathrm{C}$ and $289^{\circ} \mathrm{C}$ for $\mathrm{U}_{\mathrm{f}}$ to $272{ }^{\circ} \mathrm{C}$ and $299{ }^{\circ} \mathrm{C}$ for $\mathrm{W}_{\mathrm{f}}$ and $292{ }^{\circ} \mathrm{C}$ and $313{ }^{\circ} \mathrm{C}$ for $\mathrm{A}_{\mathrm{f}}$ ). This translates to the removal of hemicelluloses and pectins, which were included in the solubles content reported above.

Table 2. First TGA mass loss at $160{ }^{\circ} \mathrm{C}$ and temperatures corresponding to $5 \%$ and $10 \%$ weight loss for untreated and treated hemp fibers.

\begin{tabular}{cccc}
\hline Sample & First Mass Loss (\%) at $\mathbf{1 6 0} \mathbf{\circ}^{\circ} \mathbf{C}$ & $\mathbf{T}_{\mathbf{5}}\left({ }^{\circ} \mathbf{C}\right)$ & $\mathbf{T}_{\mathbf{1 0}}\left({ }^{\circ} \mathbf{C}\right)$ \\
\hline $\mathrm{U}_{\mathrm{f}}$ & 1.4 & 254 & 289 \\
$\mathrm{~W}_{\mathrm{f}}$ & 0.3 & 272 & 299 \\
$\mathrm{WS}_{\mathrm{f}}$ & 0.3 & 278 & 305 \\
$\mathrm{~A}_{\mathrm{f}}$ & 0.3 & 292 & 313 \\
$\mathrm{AS}_{\mathrm{f}}$ & 0.3 & 288 & 310 \\
\hline
\end{tabular}

The reduced truncation of $A_{f}$ dTGA curve (Figure $5 b$ ) compared to $U_{f}$ also confirms the removal of hemicellulose matter [6], which corresponds to the FTIR observation. Likewise, Table 2 reveals an improvement in thermal stability for $\mathrm{WS}_{\mathrm{f}}$ compared to $\mathrm{W}_{\mathrm{f}}$, which is mainly due to the effect of silane molecules coating the fiber surface [6]; though, there seems to also have been possible additional extraction of some non-cellulosic fiber components during silane treatment as indicated by the FTIR results. Such non-cellulosic components removal after silane treatment has also been highlighted by Panaitescu et al. [21], and a similar rise in thermal degradation temperatures was obtained for fibers treated with silane after washing in water by Dayo et al. [18]. The observed $T_{5}$ and $T_{10}$ values for $\mathrm{WS}_{\mathrm{f}}, \mathrm{A}_{\mathrm{f}}$, and $\mathrm{AS}_{\mathrm{f}}$ are comparable to values reported in the literature $[18,20]$.

\subsection{Scanning Electron Microscopical (SEM) Observations}

Observation of the SEM images presented in Figure 6 shows a cleaner and clearer surface for the $\mathrm{A}_{\mathrm{f}}$ - and $\mathrm{AS}_{\mathrm{f}}$-treated fibers. This cleaner appearance is associated with substantial removal of hemicellulose and lignin from the fiber surface $[5,9,23,24]$. However, compared to the untreated fibers, $\mathrm{W}_{\mathrm{f}}$ does not appear to have removed non-cellulosic contents (most likely wax and lignin contents), while the fibers subsequently treated with silane $\left(\mathrm{WS}_{\mathrm{f}}\right.$ and $\mathrm{AS}_{\mathrm{f}}$ ) show a slightly smoother surface compared to those of $\mathrm{W}_{\mathrm{f}}$ and $A_{f}$, respectively. This outcome could be due to the additional removal of pectin and hemicellulose by the ethanol/water mixture and the formation of a siloxane layer on the fiber surface due to condensation of the silane groups that are reported to be more visible with higher amounts of silane modification (5-20\%) [8]. These generally agree with the FTIR and TGA analyses and show the differences in surface structure for the hemp fibers after treatments. SEM micrographs of the HPLA composites (Figure 7) visibly prove that the fiber treatments improved fiber distribution and individualization within the matrix in the highest order from $\mathrm{ASH}, \mathrm{AH}$, and WSH to $\mathrm{WH}$ and $\mathrm{UH}$ as a result of the non-cellulosic content removal, which has also been reported in past studies $[25,26]$. Commonly, all the composites show good fiber alignment. 

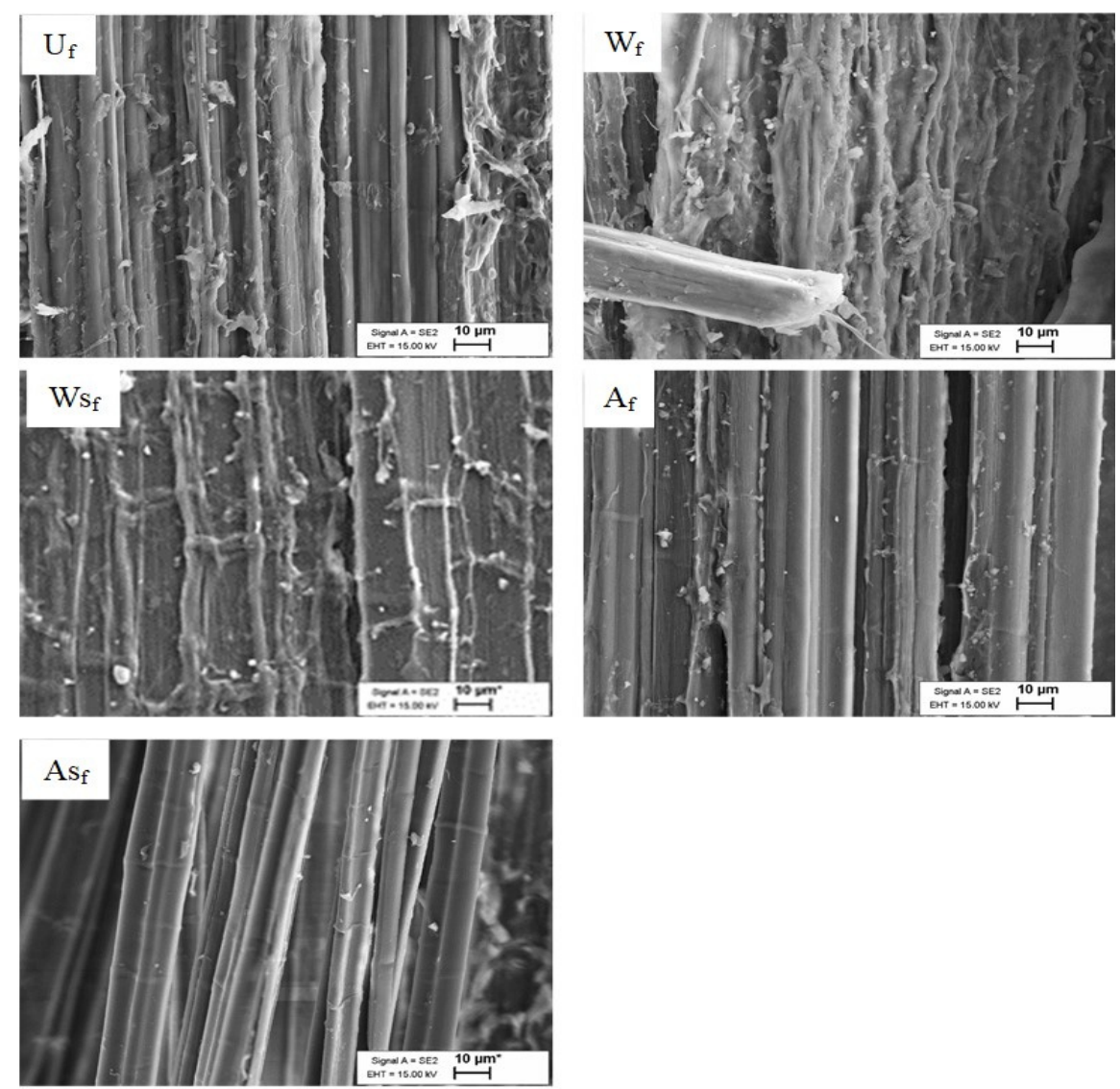

Figure 6. SEM images of $\left(\mathrm{U}_{\mathrm{f}}\right)$ untreated, $\left(\mathrm{W}_{\mathrm{f}}\right)$ water-treated, $\left(\mathrm{WS}_{\mathrm{f}}\right)$ water $+3 \%$ silane-treated, $\left(\mathrm{A}_{\mathrm{f}}\right) 5 \%$ alkali-treated, and $\left(\mathrm{AS}_{\mathrm{f}}\right) 5 \%$ alkali $+3 \%$ silane-treated hemp fiber surfaces.

\subsection{Mechanical Properties}

\subsubsection{Tensile Properties of the Hemp Fibers}

Mechanical properties (modulus of elasticity (MoE), strength and strain) are presented in Figures 8-10, respectively. On the figures, the lower and upper hinges correspond to the first and third quartiles (the 25th and 75th percentiles). We see widely scattered values for all properties (Figures 8-10, Table 3), as is often reported in the literature for hemp and other plant fibers $[2,26]$.

Table 3. Means and medians of tensile data for all combined treatments.

\begin{tabular}{ccccccccccccc}
\hline & \multicolumn{4}{c}{ Modulus (GPa) } & \multicolumn{3}{c}{ Tensile Strength (MPa) } & \multicolumn{3}{c}{ Strain\% } \\
\hline Combined & Mean & SD $^{*}$ & Median & IQR ** & Mean & SD & Median & IQR & Mean & SD & Median & IQR \\
\hline Raw & 16.6 & 8.5 & 14.1 & 11.5 & 500 & 239 & 464 & 270 & 2.93 & 1.02 & 2.70 & 1.00 \\
Water-Untreated & 14.3 & 7.9 & 12.4 & 11.1 & 376 & 220 & 336 & 257 & 2.43 & 0.78 & 2.45 & 0.78 \\
Alkali-Untreated & 15.0 & 5.2 & 15.8 & 6.7 & 381 & 189 & 369 & 234 & 2.42 & 0.91 & 2.30 & 1.20 \\
Water-Silane & 17.2 & 8.3 & 15.1 & 12.0 & 490 & 210 & 459 & 236 & 2.71 & 1.16 & 2.60 & 1.25 \\
Alkali-Silane & 15.6 & 9.0 & 13.9 & 9.4 & 466 & 287 & 390 & 295 & 2.81 & 0.89 & 2.80 & 1.25 \\
\hline
\end{tabular}

* SD = Standard Deviation; ** IQR = Interquartile Range. 

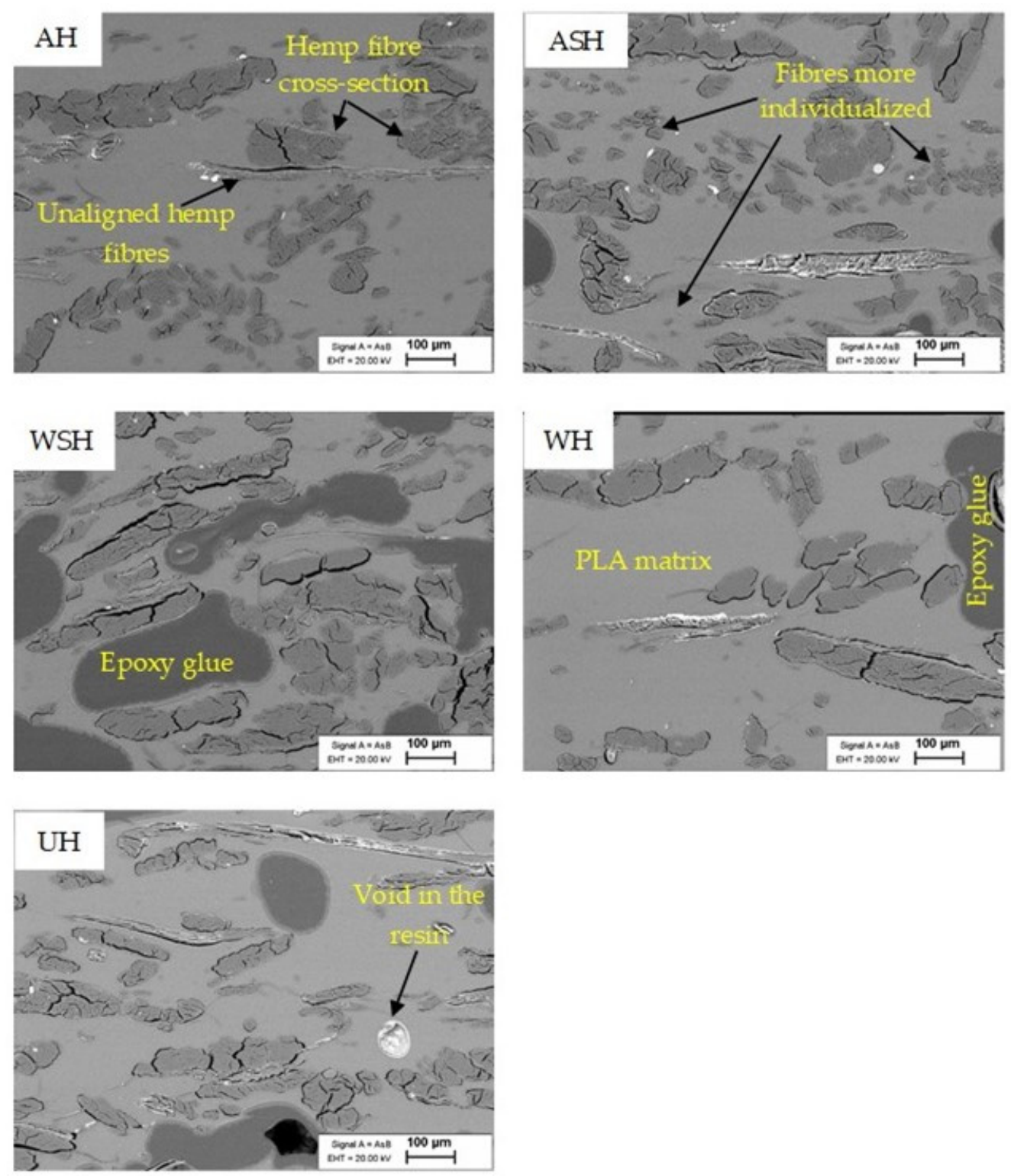

Figure 7. Cross-section SEM images of $\mathrm{UH}, \mathrm{WH}, \mathrm{WSH}, \mathrm{AH}$, and ASH composites from $30 \mathrm{wt} \%$ hemp fibers.

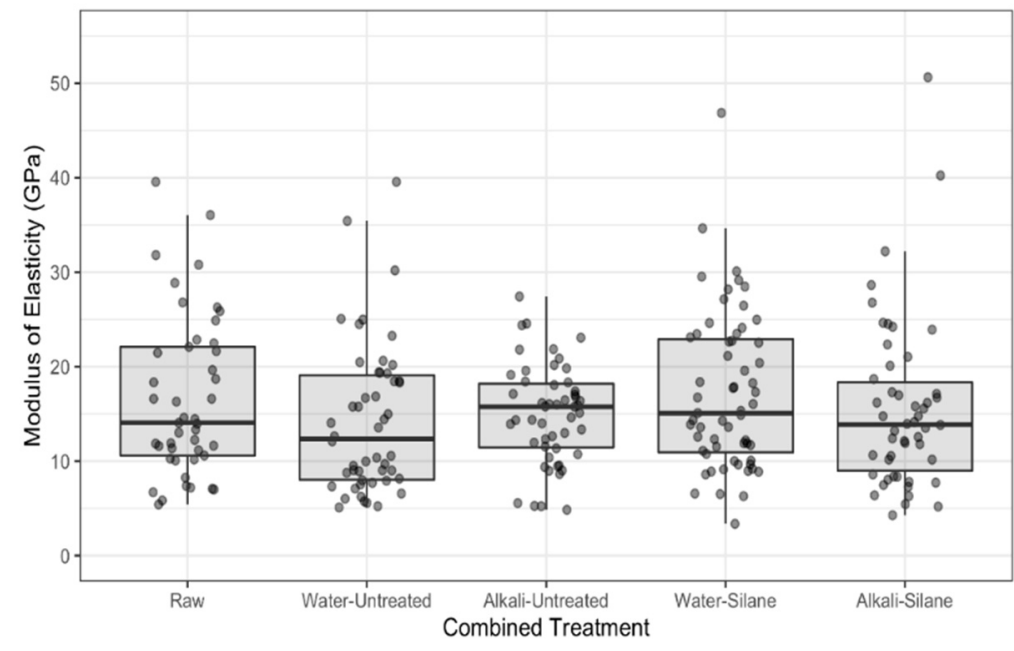

Figure 8. Modulus of elasticity for raw hemp fibers and fibers with combined treatments. 


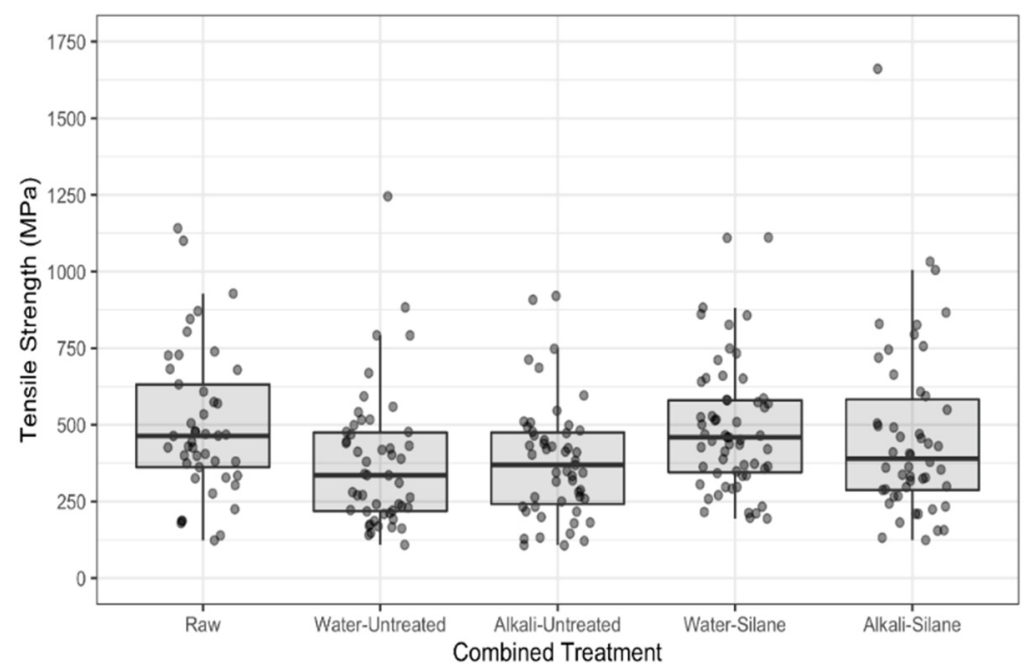

Figure 9. Tensile strength of raw hemp fibers and fibers with combined treatments.

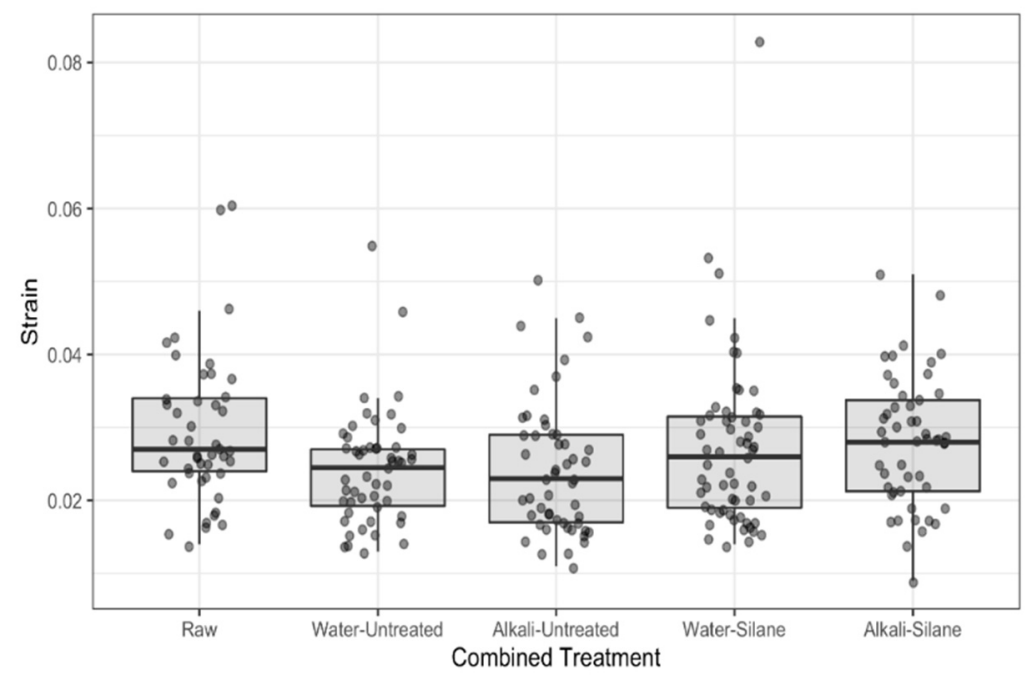

Figure 10. Strain of raw hemp fibers and fibers with combined treatments.

Table 4 presents the effect of pretreatments (none = raw fibers, water, and alkali) on the tensile properties of hemp fibers as a ratio between medians of the given treatments. We note that MoE of the hemp fibers was not affected by water or alkali pretreatments (confidence intervals for the ratios include 1). However, the tensile strength and elongation at break were both reduced after water and alkali pretreatments. The median tensile strength of raw fibers was 1.36 times greater than water pretreated fibers (95\% CI: 1.06 to 1.76) and was 1.33 times greater than fibers pretreated with alkali (95\% CI: 1.03 to 1.72). Median elongation at break was 1.23 times greater for raw fibers than alkali pretreated fibers ( $95 \%$ CI: 1.04 to 1.44 ) and was 1.2 times greater for raw fibers than for water pretreated fibers (95\% CI: 1.02 to 1.41). There was no meaningful difference in the tensile properties between fibers pretreated with water and alkali (95\% CI's include 1 in each case).

Water pretreatment generates a water uptake by the fibers, which occurs under two states in natural fibers, depending on the moisture content $[22,27,28]$ : (i) Water bound to the different biopolymers constituting the cell walls and middle lamella, involving the formation of hydrogen bonds with hydroxyl groups $\mathrm{OH}$, and (ii) free water that fills voids (micro- and macropores of cell walls and lumens) and is retained by capillary forces. Garat et al. [29] measured moisture content of $62.8 \pm 0.7 \%$ for hemp fiber bundles in immersion (compared to $60.9 \pm 0.7 \%$ for flax fiber bundles). Moreover, Pejic et al. [28] showed that lignin removal decreases the moisture sorption and increases the water retention ability of hemp fibers. Marrot et al. [13] highlighted that the raw hemp fibers of 
this study display a particularly low lignin content, which is also confirmed by the TGA analysis. We can then assume that our fibers show high water retention ability during water pretreatment. Pectins and hemicelluloses from the surface, cell wall and middle lamella are removed during water pretreatment, confirmed by the FTIR and TGA results, and we suspect changes in the component arrangements of the S2 layer that consists of highly crystallized cellulose microfibrils embedded in an amorphous polysaccharide matrix (pectins and hemicelluloses). A decrease of the median tensile strength by $36 \%$ after water pretreatments can be explained by a component rearrangement in the S2 layer, which controls the mechanical properties of the whole fiber. Le Duigou et al. [30] also observed an alteration of the structural cohesion (cell-wall peeling process) of a flax fiber following water treatment.

Table 4. Effect of pretreatments (raw fibers, water and alkali) on the tensile properties of hemp fibers and comparison of tensile properties for hemp fibers before and after silane treatment (with water and alkali pretreatments).

\begin{tabular}{|c|c|c|c|c|c|c|c|c|c|}
\hline \multirow[b]{2}{*}{ Comparison } & \multicolumn{3}{|c|}{ Tensile Strength } & \multicolumn{3}{|c|}{ Modulus } & \multicolumn{3}{|c|}{ Strain } \\
\hline & Ratio & $95 \%$ CI & $p$-Value & Ratio & $95 \%$ CI & $p$-Value & Ratio & $95 \%$ CI & $p$-Value \\
\hline Raw/Alkali & 1.3 & 1.03 to 1.72 & $0.0255 *$ & 1.05 & 0.83 to 1.33 & 0.8647 & 1.23 & 1.04 to 1.44 & $0.0092 * *$ \\
\hline Raw/Water & 1.36 & 1.06 to 1.76 & $0.0131 *$ & 1.18 & 0.93 to 1.5 & 0.2130 & 1.20 & 1.02 to 1.41 & $0.0261 * *$ \\
\hline Alkali/Water & 1.03 & 0.8 to 1.32 & 0.9641 & 1.12 & 0.89 to 1.41 & 0.4459 & 0.98 & 0.83 to 1.14 & 0.9289 \\
\hline Silane/Untreated I Alkali & 1.19 & 0.97 to 1.45 & 0.0938 & 0.97 & 0.8 to 1.18 & 0.7777 & 1.18 & 1.03 to 1.35 & $0.0187^{*}$ \\
\hline Silane/Untreated I Water & 1.38 & 1.13 to 1.67 & $0.0013 * *$ & 1.23 & 1.02 to 1.49 & $0.0294 *$ & 1.09 & 0.95 to 1.24 & 0.2041 \\
\hline
\end{tabular}

${ }^{*} p<0.05,{ }^{* *} p<0.01$. $p$-values were adjusted using Tukey's method for a family of 3 estimates. Comparisons can be interpreted as the ratio between Silane and Untreated fibres that were pretreated with Alkali (Silane/Untreated I Alkali) or Water.

Regarding alkali pretreatment, the median tensile strength was found to be $33 \%$ lower than untreated fibers. The effects of alkaline treatments on the mechanical properties of hemp fibers are controversial in the literature; Kabir et al. [9], Väisänen et al. [23] and Islam et al. [31] observed a deterioration of tensile properties (strength and modulus) that they attributed to lignin removal and other non-cellulosic components that reinforce the fibers and to potential degradation of cellulose chains [32]. On the contrary, Sawpan et al. [24] and Sair et al. [33] observed an increase of tensile properties for hemp fibers after alkali treatments that they attributed to a relaxation and reorganization of the microfibrils along the principal axis of the fiber, resulting in a more rigid structure thanks to the elimination of lignin and hemicellulose components. Besides a reduction of lignin and hemicellulose amounts [29,30], authors report a transformation of cellulose II to cellulose I [33] and an augmentation of the cellulose crystallinity [31] after application of an alkaline pretreatment to the fibers.

Furthermore, the effect of silane treatment on the tensile properties of hemp fibers pretreated with water and alkali is also shown in Table 4. In the case of alkali pretreatment, silane did not affect MoE, but fiber elongation and tensile strength were greater (strain: 1.18 times, 95\% CI: 1.03 to 1.35; tensile strength: 1.19 times, 95\% CI: 0.97 to 1.45). When pretreated with water, both $\mathrm{MoE}$ and tensile strength were greater when treated additionally with silane (MoE: 1.38 times, 95\% CI: 1.13 to 1.67; tensile strength: 1.23 times, 95\% CI: 1.02 to 1.49). There was a moderate increase in fiber elongation in this case as well. Silane couplings with cellulose microfibrils formed a layer of chemicals on the fiber surface, acting like a coating, which agrees with the FTIR and TGA results. During the tensile test, an additional shear resistance was brought by the layer of chemicals that attached to the microfibrils. Shear resistance creates higher elongation of the microfibrils, resulting in increased deformation of the fiber as highlighted by Kabir et al. [9].

\subsubsection{Tensile Properties of HPLA Composites}

From the TS results presented in Figure 11, UH shows a lower outcome of $48 \pm 2.4 \mathrm{MPa}$ (30 wt. $\%$ ) and $37 \pm 7 \mathrm{MPa}$ (50 wt. \%), compared to the neat PLA, $51 \pm 0.45 \mathrm{MPa}$. This indicates an ineffective reinforcement of PLA with untreated hemp fibers. There was a slight increase of about $6 \%$ for WH compared to UH (30 wt. \%), but no meaningful improvement 
was achieved for WSH compared to WH. On the other hand, alkali pretreatment of the hemp fibers significantly boosted the composite TS by about $14 \%$; subsequent treatment with silane added another $10 \%$ compared to AH. At the fiber level, both water and alkali pretreatments decreased TS of the fibers by about 30\%. The increase in TS for WH and AH compared to the untreated hemp fiber reinforced PLA composites, despite the treatment's negative impact on fiber performance, can be attributed to: (1) The better level of fiber individualization as observed by SEM technique, which induces a higher aspect ratio, and (2) the enhanced PLA-fiber bonding after removal of water-soluble polysaccharides in water pretreatment and removal of pectin, wax and intercellular components in alkali pretreatment. Removal of these components exposes more hydroxyl groups and increases access to cellulose sites for interlocking with the PLA matrix, which corroborates previous studies $[23,34,35]$. At the fiber scale, silane treatment increased the TS of hemp fibers pretreated with water and alkali. Additional improvement to TS observed on composites at the macroscale after silane treatment was attributable to higher fiber performance and improved fiber compatibility with the polymer matrix brought on by the silane couplings.

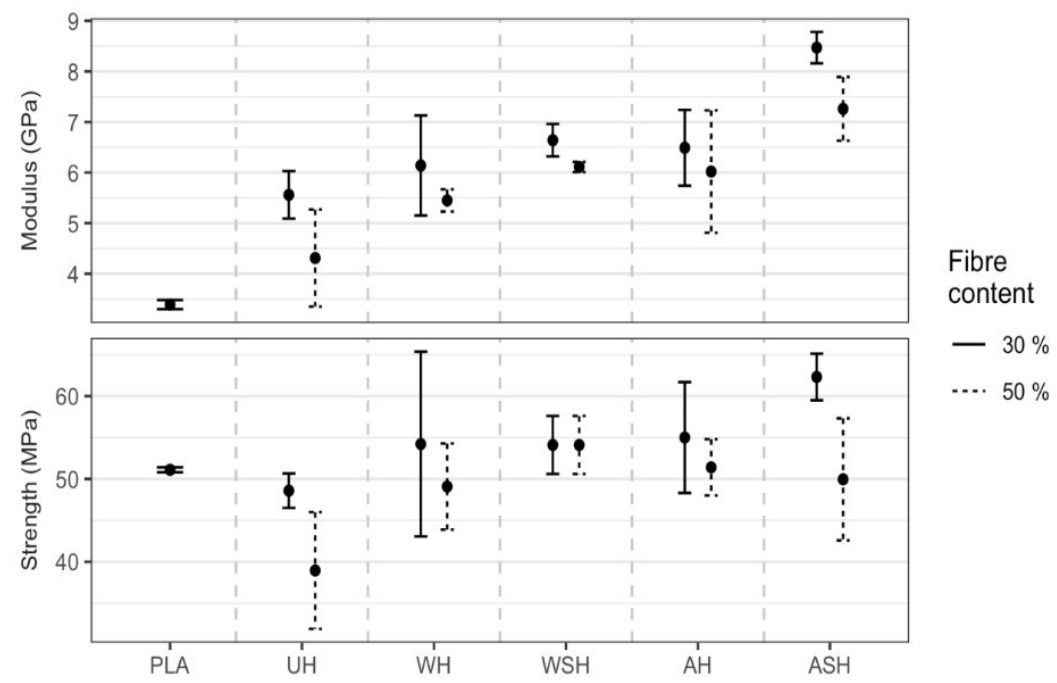

Figure 11. Medians (•) for YM and TS at 30 and $50 \mathrm{wt}$ \% hemp fiber content for untreated (UH) and treated (WH, WSH, AH, and ASH) compared to neat PLA (bars show the one interquartile range on either side of the median).

Regarding the 50 wt.\% HPLA composites, there was generally a decrease in TS compared to $30 \mathrm{wt} . \%$, which was ascribed to insufficient wetting of the fibers by the PLA matrix [24,26] and, consequently, an inefficient load transfer between fibers and matrix. Sawpan et al. [23] also showed that there was no linear improvement in TS with an increase in fiber loading from 10-30 wt.\%; moreover, previous studies show that $30 \mathrm{wt}$ \% was the maximum fiber volume fraction at which optimum composite mechanical performance was achieved [20,36]. From the result of the specimens' Young's modulus (YM), a significant rise of about $37 \%$ and $23.5 \%$ was obtained with reinforcements of 30 and $50 \mathrm{wt} . \% \mathrm{U}_{\mathrm{f}}$ compared to neat PLA due to much higher elastic modulus of the hemp fibers (Figure 8) compared to PLA (approx. 3.8 GPa based on technical data). At the fiber scale, hemp fibers' MoE was not affected by water or alkali pretreatments and showed only a slight increase for WSf. However, on the composite scale, water pretreatment increased YM by 19 and 23\% at 30 and $50 \mathrm{wt} . \%$, respectively, while alkali treatment offered an even more superior outcome of 29 and $44 \%$. Following the additional silane treatment of $\mathrm{W}_{\mathrm{f}}$ (i.e., WSH), a further improvement of 6 and 15\% was achieved at 30 and $50 \mathrm{wt} . \%$, respectively. This mirrors the outcome at the fiber scale; though not meaningful at $30 \mathrm{wt} \%$, it was very significant at $50 \mathrm{wt} . \%$, indicating better entrapment of the PLA by the fiber interpenetrating network that is due to silane molecules coating the fiber surface, as described by Xie et al. [37]. 
Likewise, for TS, YM declined at 50 wt.\%, implying inadequate fiber wetting by the PLA matrix as earlier mentioned. We clearly observed that UH exhibited the most meaningful reduction (18\%) in this regard, which is probably due to the increasingly less favorable matrix / fiber interface with higher fiber content. Overall, ASH (30 wt.\%) exhibited the best outcome of $8.51 \pm 0.2 \mathrm{GPa}$, representing a notable increase of 1.5 times $(95 \% \mathrm{CI}$ : 1.40 to 1.64 ) that of $\mathrm{UH}$.

\subsubsection{Flexural Properties of HPLA Composites}

Median flexural strength (FS) and modulus (FM) for the specimens are presented in Figure 12. Neat PLA performed better in FS than UH, WH, and WSH composites, which gave lower outcomes. The reduction in FS compared to neat PLA, after reinforcement, was $\mathrm{WSH}<\mathrm{WH}<\mathrm{UH}$ at both 30 and $50 \mathrm{wt}$.\%, implying improvement in the bonding between PLA and hemp fibers following water and a combination of water and silane fiber treatments. Alkali- and silane-treated hemp fiber reinforced composites (ASH) exhibited the most significant boost in FS (34\% at $30 \mathrm{wt} \%$ and 30\% at $50 \mathrm{wt} \%$ ), compared to neat PLA, and was, significantly, 1.5 times (95\% CI: 1.29 to 1.74) and 2 times (95\% CI: 1.92 to 2.38) greater than 30 and $50 \mathrm{wt} \% \mathrm{UH}$, respectively. AH also showed a meaningful 13\% improvement at lower fiber content compared to neat PLA. As observed, there was a similar reduction in FS with an increase in the composite fiber content from 30 to $50 \mathrm{wt} \%$. The most notable reduction was by $\mathrm{WH}(33 \%), \mathrm{UH}(26 \%)$ and $\mathrm{AH}(12 \%)$, while there was no meaningful decrease in performance for either ASH or WSH even though both exhibited about $3 \%$ lower FS at $50 \mathrm{wt} . \%$. Compared to $\mathrm{AH}$, there was an insignificant increase at $30 \mathrm{wt} . \%$ by ASH, but at $50 \mathrm{wt} . \%$, there was a reasonably better outcome (1.4 times AH; 95\% CI: 1.29 to 1.50), showing the positive influence of additional silane treatment on the hemp fibers. The higher outcomes for AH and ASH compared to UH was consistent with earlier presented results from FTIR, TGA, and SEM and also agrees with past studies [18,24,35].

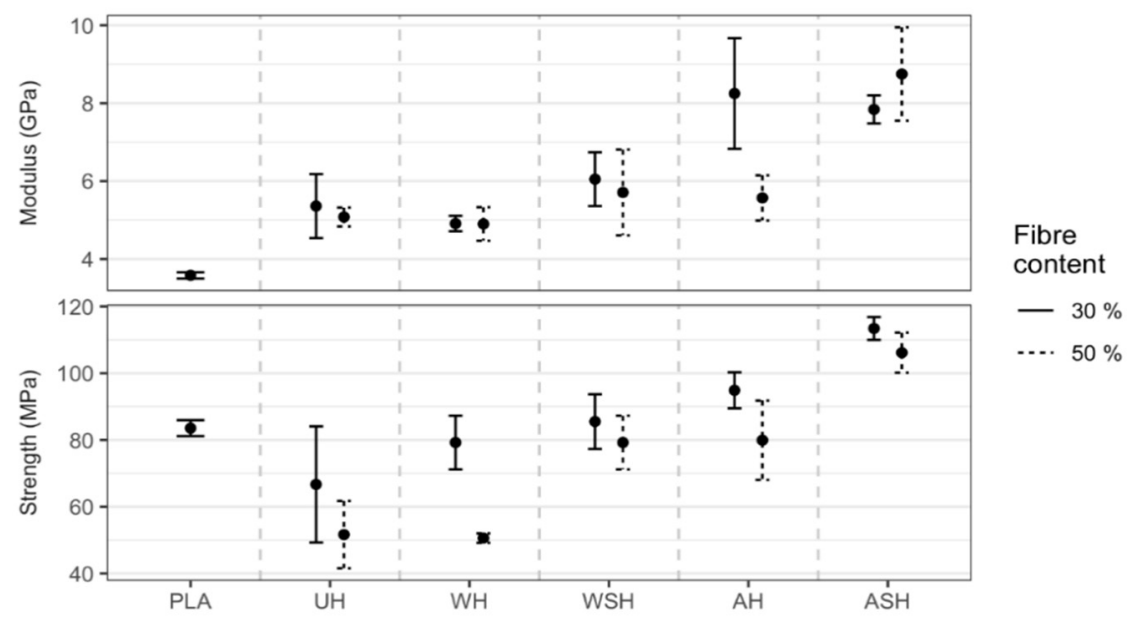

Figure 12. Medians (•) for FM and FS at 30 and $50 \mathrm{wt} . \%$ hemp fiber content for untreated (UH) and treated (WH, WSH, AH, and ASH) compared to neat PLA.

Similar to YM, composite FM also increased by about $49 \%$ after the PLA was reinforced with untreated hemp fibers (30 wt.\%) and, ultimately, by over $120 \%$ when treated hemp fibers (alkali + silane) were used. The outcome for UH compared to neat PLA was also inferred to be due to the superior elastic modulus of the hemp fibers, and the further consequential boost by ASH was the result of enhanced PLA/hemp fiber bonding after alkali and silane treatments. When we compared all composites, the increase in FM was $\mathrm{UH}=\mathrm{WH}<\mathrm{WSH}<\mathrm{AH}<\mathrm{ASH}$. Generally, composite FM also decreased with an increase in fiber content, though we noticed a $6 \%$ rise for ASH at $50 \mathrm{wt} . \%$, which was not significant and implied that there was no further improvement in performance. 
Consistent with past studies, our research reported better composite flexural performance after alkali and silane fiber pretreatments [18,24,33,34], and the 8.58 GPa FM obtained in the current study for this particular treatment approach represents one of the best outcomes achieved using the hot press method and a fiber content of $50 \mathrm{wt} . \%$. Hu and Lim [34] employed a similar fabrication and treatment method (i.e., hot pressing and alkali treatment, respectively), though with short fibers, and obtained slightly lower average FS results of $87.5 \mathrm{MPa}$ for alkali-treated hemp fiber reinforced PLA composites at $30 \mathrm{wt} . \%$. Sawpan et al. [24] obtained FS and FM of about $95 \mathrm{MPa}$ and $6.59 \mathrm{GPa}$ for alkali-treated, long-aligned $35 \mathrm{wt} . \%$ hemp fiber reinforced PLA composites that declined by about $29 \%$ and $15 \%$, respectively, at $40 \mathrm{wt} . \%$.

In addition to the mechanical properties discussed above, average density, specific tensile and flexural strength values for the HPLA composites are given in Table 5. Density of the neat PLA board is $1.24 \mathrm{~g} \mathrm{~cm}^{-3}$, which is the same value stipulated by the manufacturer and confirms the effectiveness of the fabrication approach. Densities for the composites are 1.13 to $1.23 \mathrm{~g} \mathrm{~cm}^{-3}$. There appears to be no significant difference in densities for composites of similar fiber content, but the $50 \mathrm{wt} . \%$ composites exhibit a slightly lower density compared to the $30 \mathrm{wt} . \%$ composites. Overall, the alkali pretreated and alkali + silane-treated hemp fiber reinforced composites show slightly higher density compared to the other composite variants, which could be due to consistency in hemp fiber content following the removal of most non-cellulosic elements. Lower density of the $50 \mathrm{wt} . \%$ composites could be the result of more voids, which decrease resin flow through the fibers at higher contents, and differences across all samples may also arise from fabrication irregularities, which may occur from the manual composite manufacturing processes. Pappu et al. [35] achieved specific TS and FS of (27.9 \pm 2.5$) \sigma / \rho$ and $(64.9 \pm 1.13)$ $\sigma / \rho$ for neat PLA, which increased by $27 \%$ after incorporation of hybrid fibers of hemp and flax (composite density of $1.19 \pm 0.02 \mathrm{~g} \mathrm{~cm}^{-3}$ ). Hu and Lim [34] obtained specific TS of $34.5 \sigma / \rho$ and $35.8 \sigma / \rho$ for untreated and alkali-treated hemp fiber reinforced PLA composites, respectively, at $50 \mathrm{wt} . \%$. Compared to these past studies, the current study showed slightly higher outcomes. The use of such low-density composites could offer a suitable alternative to composites from synthetic fibers, reduce carbon dioxide emissions and increase energy savings in transportation applications.

Table 5. Average density and specific mechanical properties of the neat PLA and HPLA composites.

\begin{tabular}{|c|c|c|c|c|c|c|c|c|}
\hline & Specimen & $\begin{array}{l}\text { Density } \\
\left(\mathrm{g} / \mathrm{cm}^{-3}\right)\end{array}$ & $\begin{array}{c}\text { Specific TS } \\
\sigma / \rho\end{array}$ & $\begin{array}{c}\text { Specific FS } \\
\sigma / \rho\end{array}$ & & $\begin{array}{l}\text { Density } \\
\left(\mathrm{g} / \mathrm{cm}^{-3}\right)\end{array}$ & $\begin{array}{c}\text { Specific TS } \\
\sigma / \rho\end{array}$ & $\begin{array}{c}\text { Specific FS } \\
\sigma / \rho\end{array}$ \\
\hline \multirow[t]{3}{*}{$100 \%$} & PLA & $1.24 \pm 0.01$ & $41.29 \pm 0.36$ & $68.19 \pm 2.03$ & & & & \\
\hline & UH & $1.19 \pm 0.11$ & $40.19 \pm 2.19$ & $60.92 \pm 10.51$ & & $1.13 \pm 0.05$ & $33.06 \pm 6.60$ & $47.24 \pm 5.68$ \\
\hline & WH & $1.20 \pm 0.13$ & $42.46 \pm 6.05$ & $67.05 \pm 4.54$ & & $1.13 \pm 0.10$ & $42.85 \pm 4.39$ & $47.51 \pm 5.97$ \\
\hline \multirow[t]{3}{*}{30 wt. $\%$} & WSH & $1.18 \pm 0.05$ & $43.94 \pm 3.15$ & $70.47 \pm 4.01$ & 50 wt. $\%$ & $1.13 \pm 0.10$ & $45.90 \pm 3.29$ & $71.63 \pm 4.50$ \\
\hline & $\mathrm{AH}$ & $1.23 \pm 0.02$ & $45.20 \pm 4.67$ & $77.22 \pm 2.61$ & & $1.16 \pm 0.06$ & $45.27 \pm 1.98$ & $72.59 \pm 8.03$ \\
\hline & ASH & $1.21 \pm 0.05$ & $51.00 \pm 2.64$ & $93.64 \pm 2.69$ & & $1.16 \pm 0.03$ & $46.67 \pm 6.33$ & $94.22 \pm 6.68$ \\
\hline
\end{tabular}

\section{Conclusions}

This study was an in-depth investigation into the effect of different hemp fiber surface pretreatments (water and sodium hydroxide) combined with silane treatment. At the microscale, FTIR, TGA, and SEM investigations highlighted structural alterations in the fibers, with the removal of targeted components and rearrangement in the cell wall. These structural changes influenced unitary fiber properties. At the fiber microscale, preliminary treatment tended to reduce tensile strength and elongation at break but did not affect the modulus of elasticity. Silane treatment improved tensile strength for both pretreatments and modulus of elasticity after water pretreatment. At the macroscale, both pretreatments increased the composites' tensile properties, despite their negative impact on fiber performance. This improvement was the result of a better level of fiber individualization after pretreatment and enhanced PLA-fiber bonding induced by the removal of water-soluble polysaccharides during water pretreatment and removal of pectin, wax and intercellular 
components during alkali pretreatment. Additionally, silane treatment improved composite performance thanks to the higher performance of the fibers themselves and improved fiber compatibility with the polymer matrix brought on by the silane couplings. This study showed successful development of low-density composites suitable for transportation applications, which will allow for a reduction of weight and carbon dioxide emissions. Future study will examine the influence of these chemical treatments on composite moisture/humidity sensitivity and fire performance.

Author Contributions: Validation, P.F.A. and M.D.B.; Formal Analysis, P.F.A. and M.D.B.; Visualization, P.F.A. and L.M.; Writing一original draft, P.F.A. and L.M.; Writing—review and editing, P.F.A.; L.M. and M.D.B.; Funding Acquisition, P.F.A.; J.K. and L.M.; Investigation, P.F.A., L.M., M.S. and G.L.; Conceptualization, L.M. and J.K.; Resources, J.K. and L.M.; Supervision, J.K. All authors have read and agreed to the published version of the manuscript.

Funding: This project has received funding from the European Regional Development Fund, European Union's Horizon 2020 research and innovation programme under the Marie Sklodowska-Curie Actions (grant number 898179), European Union's Horizon 2020 research and innovation programme under H2020 WIDESPREAD-2-Teaming (grant number 739574) and investment from the Republic of Slovenia and ARRS (Slovenian Research Agency) Bilateral Project Slovenia-Estonia (grant agreement number BI-EE/20-22-007).

Institutional Review Board Statement: Not applicable.

Informed Consent Statement: Not applicable.

Data Availability Statement: Not applicable.

Conflicts of Interest: Authors declare no conflict of interest.

\section{References}

1. Baley, C.; Bourmaud, A.; Davies, P. Eighty years of composites reinforced by flax fibers: A historical review. Compos. Part A Appl. Sci. Manuf. 2021, 144, 106333. [CrossRef]

2. Marrot, L.; Lefeuvre, A.; Pontoire, B.; Bourmaud, A.; Baley, C. Analysis of the hemp fiber mechanical properties and their scattering (Fedora 17). Ind. Crop. Prod. 2013, 51, 317-327. [CrossRef]

3. Merotte, J.; Le Duigou, A.; Kervoelen, A.; Bournmaud, A.; Behlouli, K.; Sire, O.; Baley, C. Flax and hemp nonwoven composites: The contribution of interfacial bonding to improving tensile properties. Polym. Test. 2018, 66, 303-311. [CrossRef]

4. Xiao, B.; Huang, Q.; Chen, H.; Chen, X.; Long, G. A fractal model for capillary flow through a single tortuous capillary with roughened surfaces in fibrous porous media. Fractals 2021, 29, 2150017. [CrossRef]

5. Liu, M.; Thygesen, A.; Summerscales, J.; Meyer, A.S. Targeted pre-treatment of hemp bast fibers for optimal performance in biocomposite materials: A review. Ind. Crop. Prod. 2017, 108, 660-683. [CrossRef]

6. Bourmaud, A.; Morvan, C.; Baley, C. Importance of fiber preparation to optimize the surface and mechanical properties of unitary flax fiber. Ind. Crop. Prod. 2010, 32, 662-667. [CrossRef]

7. Liu, M.; Meyer, A.; Fernando, D.; Silva, D.A.S.; Daniel, G.; Thygesen, A. Effect of pectin and hemicellulose removal from hemp fibers on the mechanical properties of unidirectional hemp/epoxy composites. Compos. Part A Appl. Sci. Manuf. 2016, 90, 724-735. [CrossRef]

8. Sepe, R.; Bollino, F.; Boccarusso, L.; Caputo, F. Influence of chemical treatments on mechanical properties of hemp fiber reinforced composites. Compos. Part B Eng. 2018, 133, 210-217. [CrossRef]

9. Kabir, M.M.; Wang, H.; Lau, K.T.; Cardona, F. Tensile properties of chemically treated hemp fibers as reinforcement for composites. Compos. Part B Eng. 2013, 53, 362-368. [CrossRef]

10. Coroller, G.; Lefeuvre, A.; Le Duigou, A.; Bourmaud, A.; Ausias, G.; Gaudry, T.; Baley, C. Effect of flax fibers individualisation on tensile failure of flax/epoxy unidirectional composite. Compos. Part A Appl. Sci. Manuf. 2013, 51, 62-70. [CrossRef]

11. Marrot, L.; Bourmaud, A.; Bono, P.; Baley, C. Multi-scale study of the adhesion between flax fibers and biobased thermoset matrices. Mater. Des. 2014, 62, 47-56. [CrossRef]

12. Brounstein, Z.; Yeager, C.M.; Labouriau, A. Development of Antimicrobial PLA Composites for Fused Filament Fabrication. Polymers 2021, 13, 580. [CrossRef]

13. Marrot, L.; Alao, P.F.; Mikli, V.; Kers, J. Properties of frost-retted hemp fibers for the reinforcement of composites. J. Nat. Fibers 2021, in press.

14. R Core Team. R: A Language and Environment for Statistical Computing; R Foundation for Statistical Computing: Vienna, Austria, 2019. Available online: http:/ / www.r-project.org/index.html (accessed on 16 February 2021).

15. RStudio Team. RStudio: Integrated Development for R; RStudio, PBC: Boston, MA, USA, 2020. Available online: http://www. rstudio.com/ (accessed on 16 February 2021). 
16. Wickham, H.; Averick, M.; Bryan, J.; Chang, W.; McGowan, L.; François, R.; Grolemund, G.; Hayes, A.; Henry, L.; Hester, J.; et al. Welcome to the Tidyverse. J. Open Source Softw. 2019, 4, 1686. [CrossRef]

17. Lenth, R.; Buerkner, P.; Herve, M.; Love, J.; Riebl, H.; Singmann, H. Emmeans: Estimated Marginal Means, Aka Least-Squares Means 2020. Available online: https:// cran.r-project.org/web/packages/emmeans/emmeans.pdf (accessed on 16 February 2021).

18. Dayo, A.Q.; Zegaoui, A.; Nizamani, A.A.; Kiran, S.; Wang, J.; Derradji, M.; Cai, W.-A.; Liu, W.-B. The influence of different chemical treatments on the hemp fiber/polybenzoxazine based green composites: Mechanical, thermal and water absorption properties. Mater. Chem. Phys. 2018, 217, 270-277. [CrossRef]

19. Rasheed, M.; Jawaid, M.; Parveez, B.; Hussain Bhat, A.; Alamery, S. Morphology, Structural, Thermal, and Tensile Properties of Bamboo Microcrystalline Cellulose/Poly(Lactic Acid)/Poly(Butylene Succinate) Composites. Polymers 2021, 13, 465. [CrossRef] [PubMed]

20. Viscusi, G.; Barra, G.; Verdolotti, L.; Galzerano, B.; Viscardi, M.; Gorrasi, G. Natural fiber reinforced inorganic foam composites from short hemp bast fibers obtained by mechanical decortation of unretted stems from the wastes of hemp cultivations. Mater. Today Proc. 2020, 34, 176-179. [CrossRef]

21. Panaitescu, D.M.; Fierascu, R.C.; Gabor, A.R.; Nicolae, C.A. Effect of hemp fiber length on the mechanical and thermal properties of polypropylene/SEBS/hemp fiber composites. J. Mater. Res. Technol. 2020, 9, 10768-10781. [CrossRef]

22. Placet, V.; Day, A.; Beaugrand, J. The influence of unintended field retting on the physicochemical and mechanical properties of industrial hemp bast fibers. J. Mater. Sci. 2017, 52, 5759-5777. [CrossRef]

23. Väisänen, T.; Batello, P.; Lappalainen, R.; Tomppo, L. Modification of hemp fibers (Cannabis Sativa L.) for composite applications. Ind. Crop. Prod. 2018, 111, 422-429. [CrossRef]

24. Sawpan, M.A.; Pickering, K.L.; Fernyhough, A. Effect of various chemical treatments on the fiber structure and tensile properties of industrial hemp fibers. Compos. Part A Appl. Sci. Manuf. 2011, 42, 888-895. [CrossRef]

25. Sood, M.; Dwivedi, G. Effect of fiber treatment on flexural properties of natural fiber reinforced composites: A review. Egypt. J. Pet. 2018, 27, 775-783. [CrossRef]

26. Bourmaud, A.; Beaugrand, J.; Shah, D.U.; Placet, V.; Baley, C. Towards the design of high-performance plant fiber composites. Prog. Mater. Sci. 2018, 97, 347-408. [CrossRef]

27. Engelund, E.T.; Thygesen, L.G.; Svensson, S.; Hill, C.A.S. A critical discussion of the physics of wood-water interactions. Wood Sci. Technol. 2013, 47, 141-161. [CrossRef]

28. Pejic, B.M.; Kostic, M.M.; Skundric, P.D.; Praskalo, J.Z. The effects of hemicelluloses and lignin removal on water uptake behavior of hemp fibers. Bioresour. Technol. 2008, 99, 7152-7159. [CrossRef]

29. Garat, W.; Le Moigne, N.; Corn, S.; Beaugrand, J.; Bergeret, A. Swelling of natural fiber bundles under hygro- and hydrothermal conditions: Determination of hydric expansion coefficients by automated laser scanning. Compos. Part A Appl. Sci. Manuf. 2020, 131, 105803. [CrossRef]

30. Le Duigou, A.; Bourmaud, A.; Balnois, E.; Davies, P.; Baley, C. Improving the interfacial properties between flax fibers and PLLA by a water fiber treatment and drying cycle. Ind. Crop. Prod. 2012, 39, 31-39. [CrossRef]

31. Islam, M.S.; Pickering, K.L.; Foreman, N.J. Influence of alkali treatment on the interfacial and physico-mechanical properties of industrial hemp fiber reinforced polylactic acid composites. Compos. Part A Appl. Sci. Manuf. 2010, 41, 596-603. [CrossRef]

32. Beckermann, G.W.; Pickering, K.L. Engineering and evaluation of hemp fiber reinforced polypropylene composites: Fiber treatment and matrix modification. Compos. Part A Appl. Sci. Manuf. 2008, 39, 979-988. [CrossRef]

33. Sair, S.; Oushabi, A.; Kammouni, A.; Tanane, O.; Abboud, Y.; Hassani, F.O.; Laachachi, A.; El Bouari, A. Effect of surface modification on morphological, mechanical and thermal conductivity of hemp fiber: Characterization of the interface of hemp -Polyurethane composite. Case Stud. Therm. Eng. 2017, 10, 550-559. [CrossRef]

34. Hu, R.; Lim, J.-K. Fabrication and Mechanical Properties of Completely Biodegradable Hemp Fiber Reinforced Polylactic Acid Composites. J. Compos. Mater. 2007, 41, 1655-1669. [CrossRef]

35. Pappu, A.; Pickering, K.L.; Thakur, V.K. Manufacturing and characterization of sustainable hybrid composites using sisal and hemp fibers as reinforcement of poly (lactic acid) via injection moulding. Ind. Crop. Prod. 2019, 137, 260-269. [CrossRef]

36. Mazian, B.; Bergeret, A.; Benezet, J.C.; Malhautier, L. Influence of field retting duration on the biochemical, microstructural, thermal and mechanical properties of hemp fibers harvested at the beginning of flowering. Ind. Crop. Prod. 2018, 116, 170-181. [CrossRef]

37. Xie, Y.; Hill, C.A.S.; Xiao, Z.; Militz, H.; Mai, C. Silane coupling agents used for natural fiber/polymer composites: A review. Compos. Part A Appl. Sci. Manuf. 2010, 41, 806-819. [CrossRef] 